\title{
Simultaneous adsorption behaviour of heavy metals from Oil Mill Wastewater onto natural clay
}

\author{
Hanane Ait Hmeid ${ }^{1, *}$, Mustapha Akodad ${ }^{1}$, Mourad Baghour ${ }^{1}$, Abdelmajid Moumen ${ }^{1}$, Ali Skalli ${ }^{1}$, Hicham Guedarri $^{1}$, \\ Yassine El Yousfi ${ }^{2}$, Mostapha Maach ${ }^{1}$, Ouassila Riouchi ${ }^{1}$ and Ghizlane Azizi ${ }^{1}$
}

\begin{abstract}
${ }^{1}$ Laboratory of Biology, Geoscience, Physics and Environment (LBGPE), Multidisciplinary Faculty of Nador, Mohamed First University, 60700 Nador, Morocco.

${ }^{2}$ Water and Environmental Management Unit (WEMU), National School of Applied Sciences, Abdelmalek Essaadi University, 32003 Al Hoceima, Morocco.
\end{abstract}

\begin{abstract}
The present work reports the synergistic and inhibitory adsorption effects involved in the multicomponent adsorption of heavy metal ions (Fe (II), $\mathrm{Pb}$ (II)), and major elements from oil mill liquid waste (OMW) using natural bentonite as adsorbent cames from Nador (North-East Morocco). Morocco is one of the most olive oil producing Mediterranean countries. This industry, which is so beneficial to the national economy, leaves two toxic and non-biodegradable residues (liquid/solid). OMW or margin is a current liquid pollutant that has been listed by the United States Environmental Protection Agency (EPA). The classical methods used for phenol removal are expensive or limited to large-scale applications such as biological and thermal decomposition methods. The margins used in the studies were collected from a semimodern oil mill (Nador-Morocco). The results of the physicochemical analyses showed that the effluents of the oil mills showed that they are highly polluted, in particular the suspended solids, COD, and iron contents of around $154.82(\mathrm{mg} / \mathrm{l})$ and copper $31.72(\mathrm{mg} / \mathrm{l})$. Samples of OMW mixed with raw bentonites at different percentages vary between $10 \%$ and $80 \%$. Different interactions between bentonite and metal ions dealing with the decrease of the concentrations. This study proves that this bentonite is an effective adsorbent for the elimination of heavy metals from OMW.
\end{abstract}

\section{Introduction}

Agricultural production is one of the primary sources of waste $[1,2]$. In several countries where olive oil is produced, the olive oil production of these countries represents $94 \%$ of world production [3-5]. Thus, the olive oil extraction process has large amounts of waste [6]. These residues can be in liquid or solid form and contain important phytochemicals with high added value. The liquid part of these wastes is named "margin" or "Oil Mill Wastewater" (OMW). By the way, the margins are strongly concentrated in organic matter, which is not very biodegradable and highly toxic [5]. They are made of water, organic compounds, and inorganic compounds.

The phenolics are identified as priority pollutants because they are harmful to organisms at low concentrations [7, 8]. As well as, hazardous pollutants because of their potential danger to human health [9]. On the other hand, inorganic compounds are manifested by heavy metals and major elements.

\footnotetext{
*Corresponding author: hanane.aithmeid@gmail.com; h.aithmeid@ump.ac.ma
}

Heavy metal contamination is one of the major concerns in today's world $[1,10]$.

Heavy metals are defined as metallic elements that have a relatively high density compared to water and is toxic or poisonous even at low concentration [6, 3]. Generally, heavy metals are toxic $[11,12]$. So in our study, we used bentonites clay as an adsorbent and the margin as adsorbate. Bentonite is a clay mineral particle with two tetrahedral silica sheets and one aluminium octahedral sheet, and the main mineral is montmorillonite which has a double diffusion layer [13, 14]. The margin used in this study it is a highly polluting and harmful acidic effluent of an organic nature, with a $\mathrm{pH}$ of around 4, total polyphenols of $9.17 \mathrm{~g} . \mathrm{L}^{-1}$, total phosphorus of $1.16 \mathrm{mg} . \mathrm{L}^{-1}$ and high COD was 172.72 g.L $\mathrm{L}^{-1}[15]$.

Concerning the bentonite clay used in this work characterized by a very high water retention capacity and therefore a high swelling capacity [16], $\mathrm{CaCO}_{3}$ was very low [17], it has high porosity and permeability [18] is also characterized by a significant specific surface area [19]. This study therefore, aims at developing a 
low-cost novel adsorbent of removing $\mathrm{Fe}$ (II), $\mathrm{Pb}$ (II) and major elements.

\section{Materials and methods}

\subsection{Materials}

Raw bentonite acquired from North-East Morocco was employed as the adsorbent material. Oil mill liquid waste used in this research was collected from the city of Nador, North-East Morocco (Fig. 1). The different properties of the studied bentonite are presented in table 1. Firstly, bentonite sample was dried at $40^{\circ} \mathrm{C}$ for $48 \mathrm{~h}$, and then characterized by particle size distribution, $\mathrm{X}$ ray diffraction (XRD), Infrared Spectroscopy (FTIR), X-ray fluorescence (XRF), and Atterberg limit. The particle size distribution of the raw bentonite has been determined by was determined by sedigraphy with the SediGraph III device, following the standards ASTM D422-C958-E1617 (Laboratory Prove, Geotechnical Centre of the University of Siena) [20]. The mineralogical composition was identified by X-ray diffraction using $X$ 'pert HighScore, was used in the range of $0-80^{\circ}$ at the scan speed of $4 \% \mathrm{~min}$ with copper anticathode $\mathrm{CuK} \alpha$ radiation $(\lambda=0.1918 \AA$, $40 \mathrm{kV}$, $40 \mathrm{~mA})$. The quantitative mineralogical analysis was obtained from the powder XRD data using an internal standard for each mineral [21]. Chemical analysis of the major elements was carried out by X-ray fluorescence spectroscopy (XRF). Plasticity was obtained by determining Atterberg limits: liquid limit (IL), plastic limit (PL) plasticity and index (PI) with stand ASTM D3418 1983 [22]. Test Method for Shrinkage Factors of bentonite by the Mercury Method [23].

Table 1. Granulometric and geotechnical characteristics of Nador bentonite.

\begin{tabular}{|l|l|l|l|l|l|l|l|l|l|}
\hline Sample & \% Gravel & \% Sand & \% Limon & \% Clay & $\mathrm{Cu}$ & \% PL & \% LL & \% PI & $\% \mathrm{Ws}$ \\
\hline BM & 0.1 & 43.9 & 38.7 & 17.3 & 96.2 & 44.8 & 90.7 & 45.9 & 15.5 \\
\hline
\end{tabular}

\footnotetext{
* $\mathbf{B}_{\mathrm{M}}$ : Moroccan bentonite; Cu: Uniformity coefficient; PL: plasticity limit; LL: Liquidity limit; PI: plasticity index; $\mathbf{W}_{\mathrm{s}}$ : shrinkage limit.
}

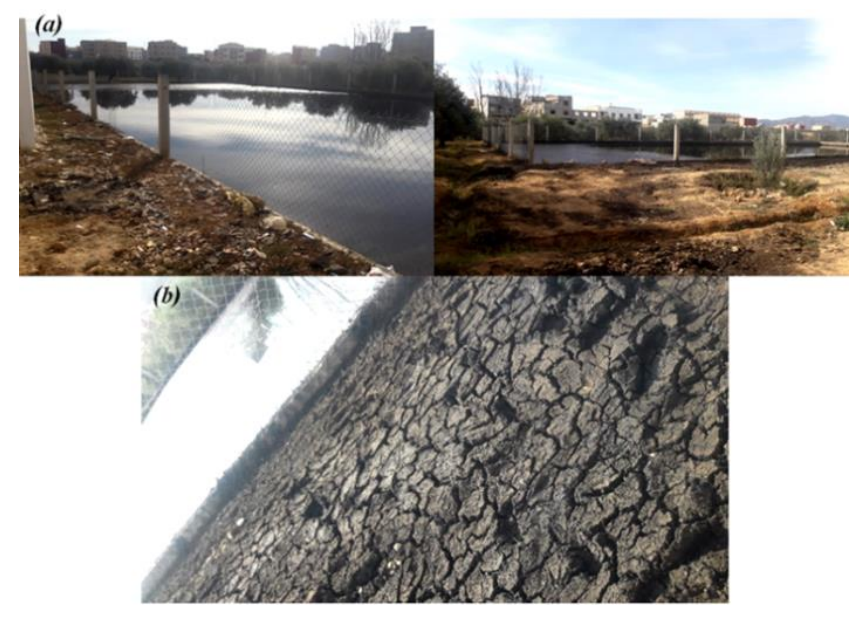

Fig.1. Olive oil extraction site (Nador - Morocco); (a) Storage of margins in basins; (b) Harmful effects of margins on soil quality.

\subsection{Measured parameters}

In this study, we have taken oil mill liquid waste as an adsorbate. In order to ensure a satisfactory including the preparation of the mixes adsorbent / adsorbate follows loads: $5 \%, 10 \%, 30 \%, 50 \%, 70 \%$, and $90 \%$. The contents of iron, lead, potassium and sodium, were analyzed by atomic absorption spectrometry (model AFP100, Biotech Management Engineering Co. Ltd., UK) [24]. Nitrogen (NTK) dosing, were performed according to the Kjeldahl method described by Bargaz et al (2012) [25]. It was determined by the mineralization of the samples in sulfuric acid of organic nitrogen in the presence of selenium $\left(\mathrm{K}_{2} \mathrm{SO}_{4}\right)$.

Chemical oxygen demand (COD) was determined using the Standard Method for the Examination of Water and Wastewater [26]. Total phosphorus was measured after mineralization in acid conditions with sodium persulfate at $200^{\circ} \mathrm{C} / 2 \mathrm{~h}$, followed by an analysis of orthophosphates according to the methods standardized by AFNOR (1997) [27]. The determination of phenols was quantified with $200 \mu \mathrm{l}$ of FolinCioccalteu according to the process recommended by Macheix et al. 1990 [28]. The absorbance reading of the solution was read at the wavelength of maximum dye using a UV-Vis spectrophotometer. The mass per cent of the removal metal ion was calculated using the following equation (1) [29]:

$$
\% \text { Removal }=(\mathrm{Ci}-\mathrm{Ce} / \mathrm{Ci}) \times 100
$$

Where $\mathrm{Ci}$ and $\mathrm{Ce}$ are the initial and final equilibrium concentrations (mg. $\left.\mathrm{L}^{-1}\right)$.

\section{Results and discussion}

\subsection{Characterization of bentonite}

\subsubsection{Particle distribution}

Table 1 presents the percentages of particle size fractions of the bentonite used in this work. The Nador bentonite analyzed show a wide variation 
in particle size distribution; four particle size fractions were identified: clay $(17.3 \%)$, silt $(38.7 \%)$, sand $(43.9 \%)$ and gravel $(0.1 \%)$. The grain sizes of clay characterize by the uniformity coefficient or Hazen coefficient allows to express the spread of the curve granulometric, and the curvature coefficient is used to describe the shape of the particle size curve [30]. The particle size curves of the bentonite investigated is well spread out (Fig. 2), although the value has a uniformity coefficient greater than $2(\mathrm{Cu}=96.2)$ [31].

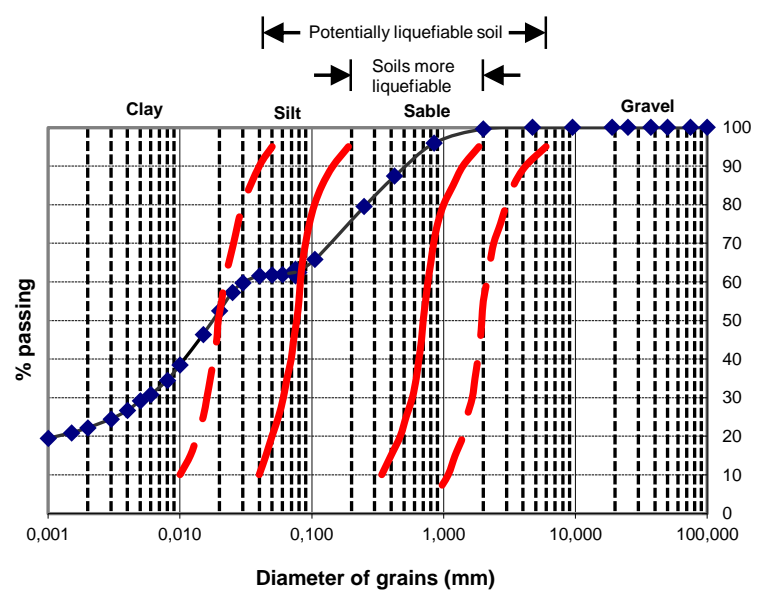

Fig. 2. Particle size distribution curve and limit of liquefiability potential according to Tsuchida (1970) [32].

\subsubsection{Mineralogical composition}

The results obtained from the analysis of the diffractograms of the total rock show that the mineralogical composition is diversified (fig. 3 a). The samples consist mainly of anorthite $(56.04 \%)$ feldspar $(20.34 \%), \quad$ and montmorillonite $(15.34 \%$ ) (fig. 3 b), with moderate cristobalite contents $(4.85 \%)$ ). Zeolite $(1.43 \%)$, quartz $(1.34 \%)$ and muscovite $(0.62 \%)$ are presents as traces in the bentonite samples. These results are complemented by infrared spectroscopy (FTIR) (fig. 4). A simple analysis of the spectra indicated the presence of a strong absorption peak located at $3632 \mathrm{~cm}^{-1}$, characteristics of $\mathrm{O}-\mathrm{H}$ stretching vibration in the bentonite structure [32-34]. Other bands were assigned to the vibration $\mathrm{H}-\mathrm{O}-\mathrm{H}$ around 3626 and $1635 \mathrm{~cm}^{-1}$ [35]. An intense band between 1035 and $465 \mathrm{~cm}^{-1}$ indicates the stretching vibration of Si-O corresponding to quartz and cristobalite [36].

The one located at $520 \mathrm{~cm}^{-1}$ is related to the elongation vibrations of the Si-O-Al bonds [37].

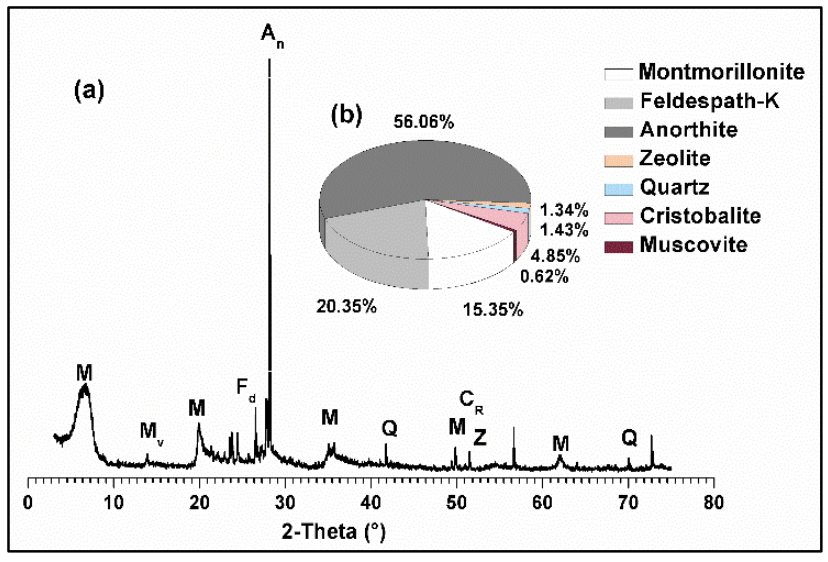

Fig. 3. (a) Total mineralogical composition obtained by Xray diffraction; (b) Semi-quantitative estimation of the total mineralogy of Nador bentonite.

*Legend: $\mathbf{Q}=$ Quartz; $\mathbf{M}=$ Montmorillonite; $\mathbf{F}_{\mathbf{d}}=$ Feldspar; $\mathbf{C}_{\mathbf{R}}=$ Cristobalite; $\mathbf{Z}=$ Zeolite $\mathbf{M}_{\mathbf{v}}=$ Muscovite $\mathbf{A} \mathbf{n}=$ Anorthite.

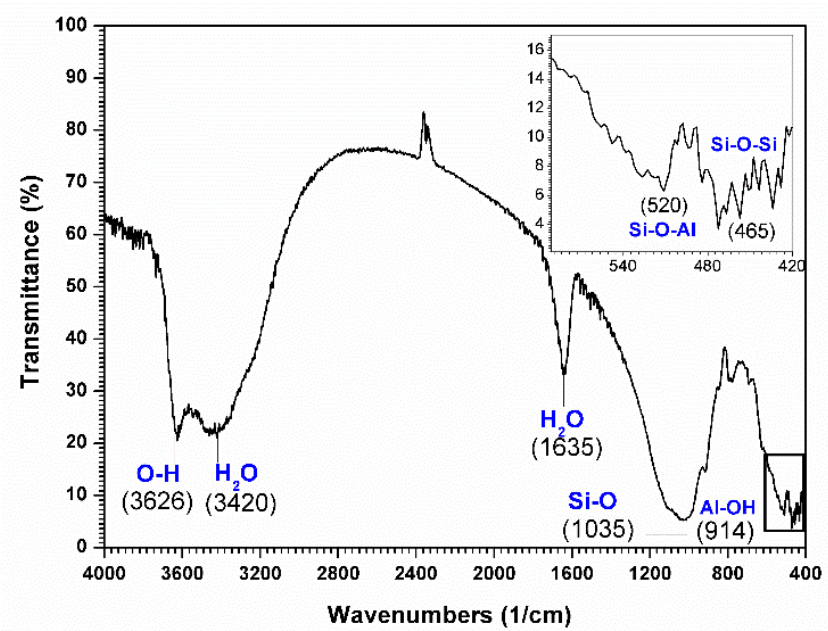

Fig. 4. Typical bentonite spectrum obtained by the infrared spectroscopy.

\subsubsection{Geotechnical proprieties}

Atterberg limits are represented in the plasticity map of Casagrande. Atterberg limit test was performed through determination of Plasticity index (PI) value from the difference of liquid limit (LL) and plastic limit (PL) [14]. Natural bentonite was reported the value of LL, PL and PI were 90.7, 44.8 and 45.9, respectively (Table 1). The plasticity map shows that the bentonites used are classified as very plastic (fig. 5). The shrinkage limit $\left(\mathrm{W}_{\mathrm{S}}\right)$ of the bentonite is $15.5 \%$ (fig. 6), has a maximum volumetric weight of about 1.87 g.cm ${ }^{-3}$ (fig. 7). 


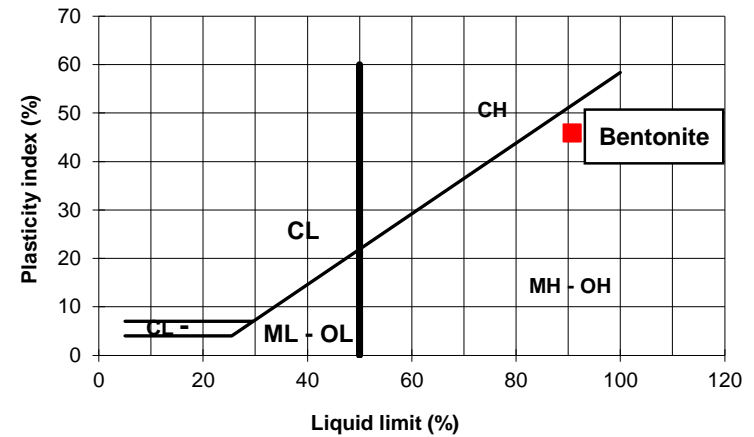

Fig. 5. Bentonite projection in the Casagrande plasticity map.

*Legend: CL : mineral clays with low to medium plasticity; ML-OL : inorganic silts and veryfine sands with very low plasticityand organic silts and silt-clay mixtures of low plasticity; $\mathbf{O H}-\mathbf{M H}$ : organic silts and clays of medium plasticity; $\mathbf{C H}$, Inorganic clays of high plasticity.

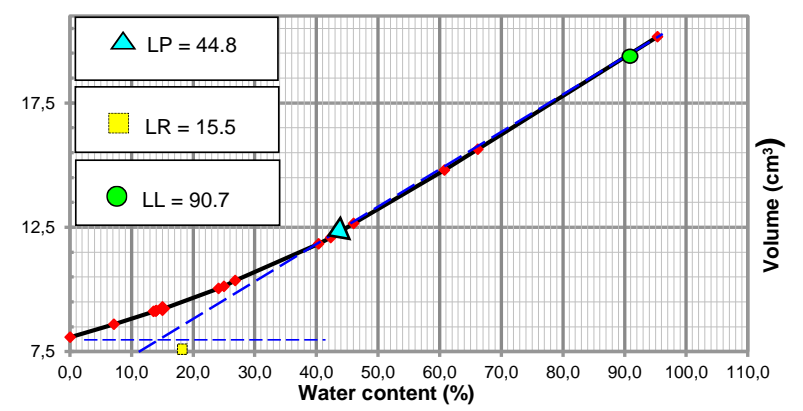

Fig. 6. Volumetric Shrinkage Curve.

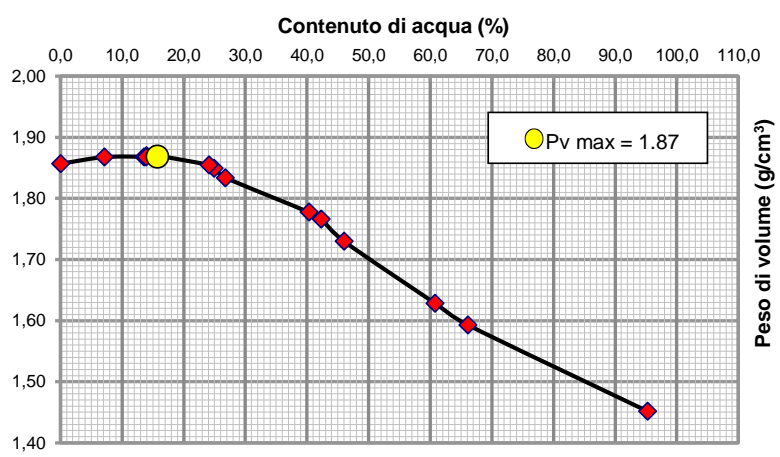

Fig. 7. Variation in volumetric weight as a function of water content

\subsubsection{Chemical composition}

Table 2 shows the XRF results of all elements presents in the natural bentonite sample. Results of the XRF show that bentonite is mainly composed of $\mathrm{Mg}$, Fe and $\mathrm{Ca}$. High levels of $\mathrm{Mg}$ and $\mathrm{Fe}$ indicate the presence of iron oxides or substitution of $\mathrm{Si}$ and $\mathrm{Al}$ by $\mathrm{Fe}$ and $\mathrm{Mg}$, also revealed that there are meager proportions of $\mathrm{P}, \mathrm{S}$, $\mathrm{Ti}, \mathrm{Mn}$...etc.

Table 2. Elements in natural clay as determined using XRF analysis.

\begin{tabular}{|l|c|c|c|c|c|c|c|c|c|c|c|c|c|c|c|c|}
\hline Element & $* \mathrm{Mg}$ & $* \mathrm{Fe}$ & $\mathrm{K}$ & $* \mathrm{Ca}$ & $\mathrm{Si}$ & $\mathrm{Al}$ & $\mathrm{P}$ & $\mathrm{S}$ & $\mathrm{Ti}$ & $\mathrm{Mn}$ & $\mathrm{Sr}$ & $\mathrm{Zr}$ & $\mathrm{Th}$ & $\mathrm{Zn}$ & $\mathrm{Y}$ & $\mathrm{Pb}$ \\
\hline Weight \% & 32.1 & 30.93 & 4.06 & 14.01 & 7.94 & 4.81 & 2.12 & 1.04 & 1.25 & 0.18 & 0.68 & 0.18 & 0.033 & 0.55 & 0.033 & 0.05 \\
\hline
\end{tabular}

(*) : maine composition.

\subsection{Purifying efficiency bentonite}

\subsubsection{Abatement of $C O D$}

Figure 8 represents the variation of the total COD concentration and the abatement rate as a function of the percentage of bentonite. COD concentrations in this study ranged from 161.03 and 62.04 g.L $\mathrm{L}^{-1}$. In turn, the COD removal rates varied between 6.77 and $64.08 \%$. So the reduction in the COD rate is most likely due to the reduced decomposition of organic matter [38, 13].

\subsubsection{Abatement of nitrogen}

NTK presents the main form of nitrogen in wastewater. The reduction of NTK concentration during the treatment of OMW is shown in Fig. 9.

The concentration of NTK fluctuates from 2.27 to 0.53 g. $\mathrm{L}^{-1}$ with an optimal removal of $77.82 \%$. The elimination of the concentration of NTK nitrogen in OMW can be explained by the texture of the bentonites that serve for the development of aerobic conditions and the denitrification process [39]. 


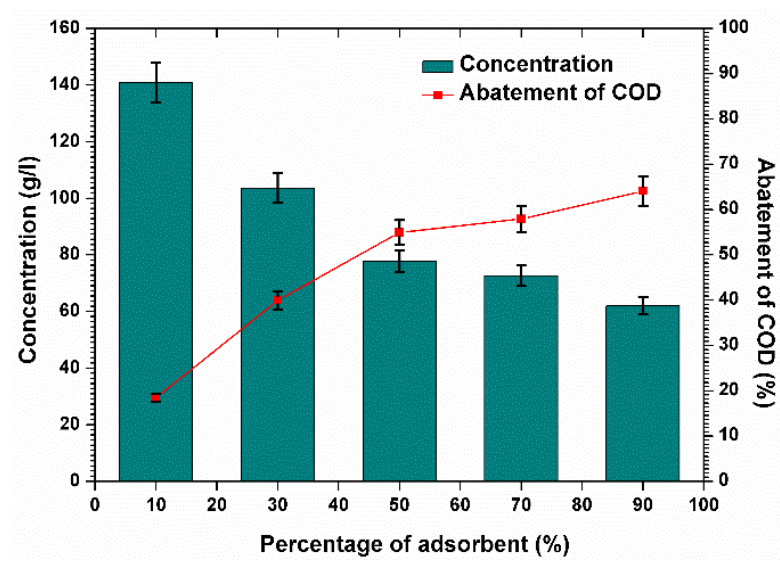

Fig. 8. Concentration and abatement of COD.

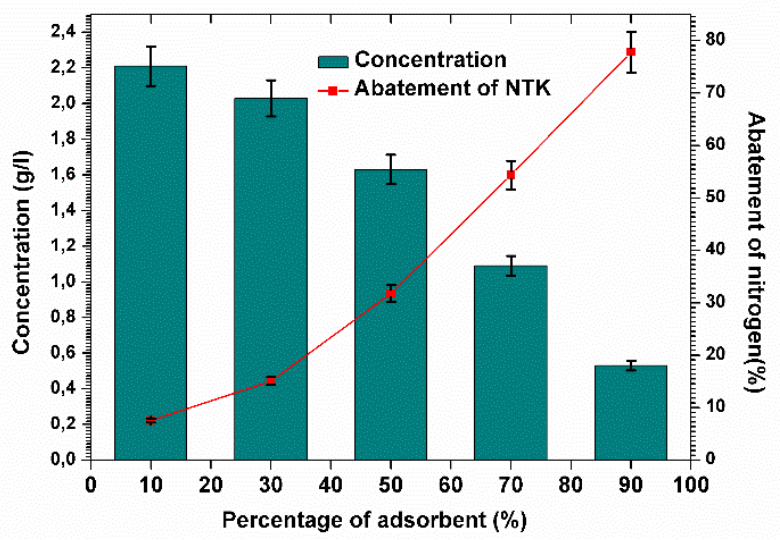

Fig. 9. Concentration and abatement of NTK.

\subsubsection{Abatement of phenol}

The analysis of the phenolic fraction as a complex of the margins allowed us to evaluate the variation and the evolution of these polyphenols according to the bentonite (fig. 10).

In this study, the maximum recorded removal rate of $76.12 \%$. In fact, the decrease of phenolic compounds would be linked to the more significant and/or higher $\mathrm{pH}[15,40]$.

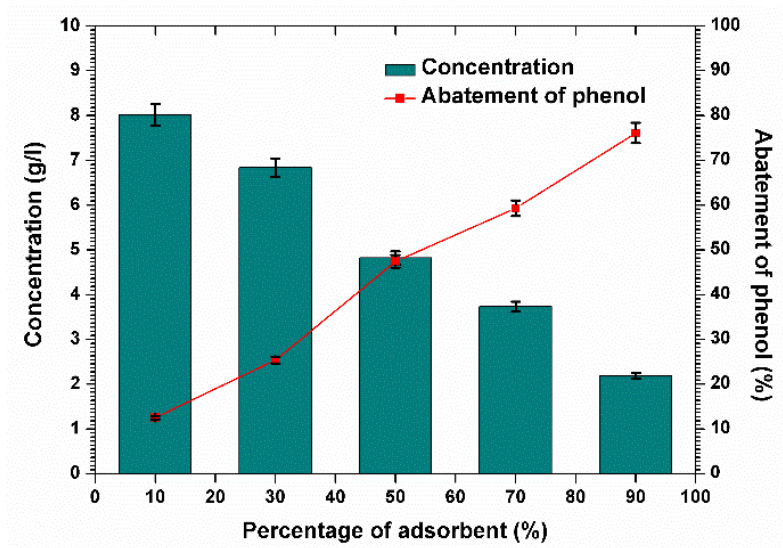

Fig. 10. Concentration and abatement of phenol.

\subsubsection{Abatement of phosphorus}

In OMW, phosphorus is present in both dissolved and particulate forms. Phosphorus can usually be removed from municipal OMW by the enhanced adsorption phosphorus removal method [41]. The maximum phosphorus retention rate of the analyzed OMW bentonite reached $94.83 \%$. The concentration decreases from 1.15 to 0.06 g. $\mathrm{L}^{-1}$ (fig. 11).

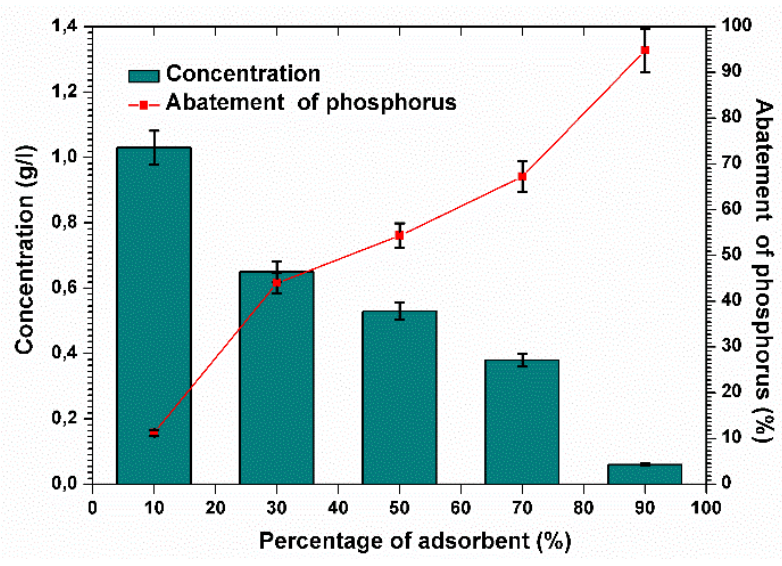

Fig. 11. Concentration and abatement of phosphorus.

\subsubsection{Abatement of major elements}

The evolution of the reduction of the element major $\mathrm{K}$ and $\mathrm{Na}$ are presented successively in figure 12 and 13. The concentration of potassium (K) diminishes from 6.14 to 4.64 g.L. $\mathrm{L}^{-1}$ (fig. 12), including abatement rates ranging from 1 to $26 \%$. Concerning the concentrations of sodium (Na) ranging from 0.93 g.L $\mathrm{L}^{-1}$ to 0.39 g. $\mathrm{L}^{-1}$, corresponds to the removal rate of $\mathrm{Na}$ increased from 10.58 to $62.5 \%$ (fig. 13). Our bentonite is characterized by the strong plasticity, whose mineralogical composition indicates significant contents of montmorillonite, although the low content of $\mathrm{K}$ and $\mathrm{Na}$ (Table 2). These data may explain the considerable rate of $\mathrm{K}$ and $\mathrm{Na}$ removal. 


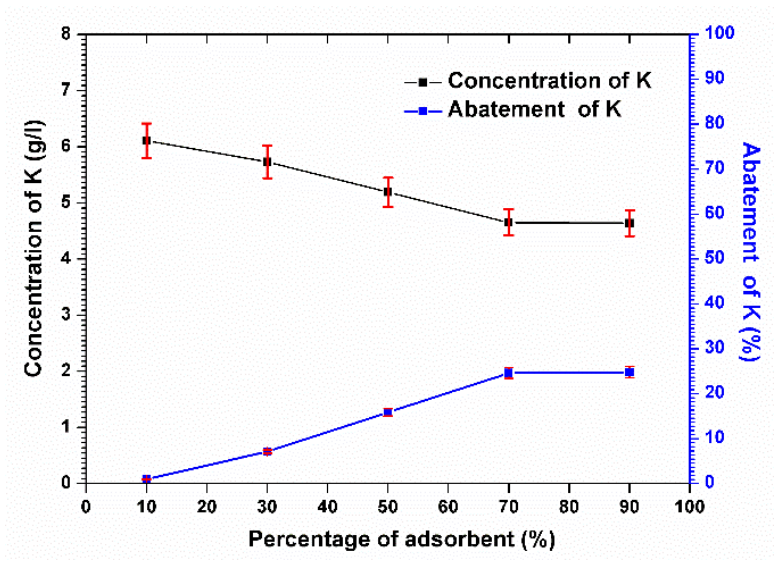

Fig. 12. Concentration and reduction of potassium.

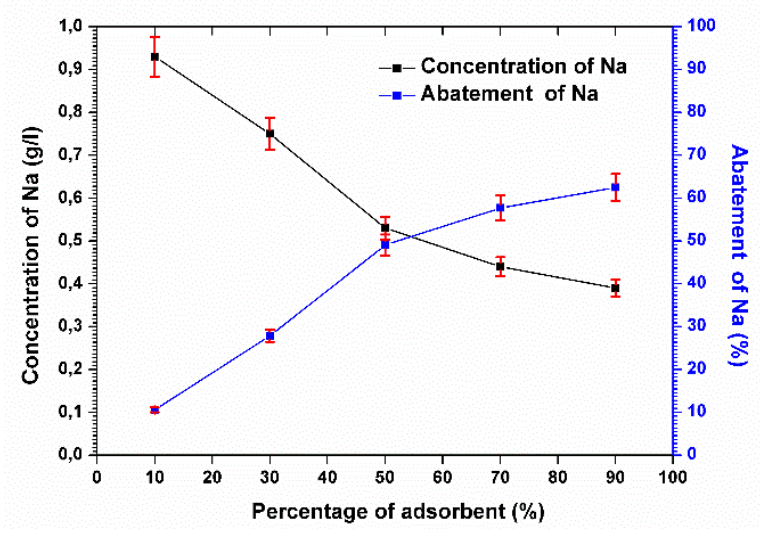

Fig. 13. Concentration and reduction of sodium.

\subsubsection{Abatement of heavy metals}

Concentration and reduction of heavy metals in margin by bentonite are shown in the following figures 14 and 15. The iron concentrations were lowered from 147.86 to 55.93 g.L L $^{-1}$. Of which the optimal reduction of iron was of the order of $63.87 \%$ (fig. 14). Nonetheless, the concentration of lead recorded has significantly decreased from 1.11 to 0.01 g. $\mathrm{L}^{-1}$, corresponds to elimination rates ranging from 78.98 to $99.81 \%$ (fig. 15 ). So, can be explained by the decreases of the iron, which is due to the precipitation of metal ions in the form of hydroxide compounds [42].

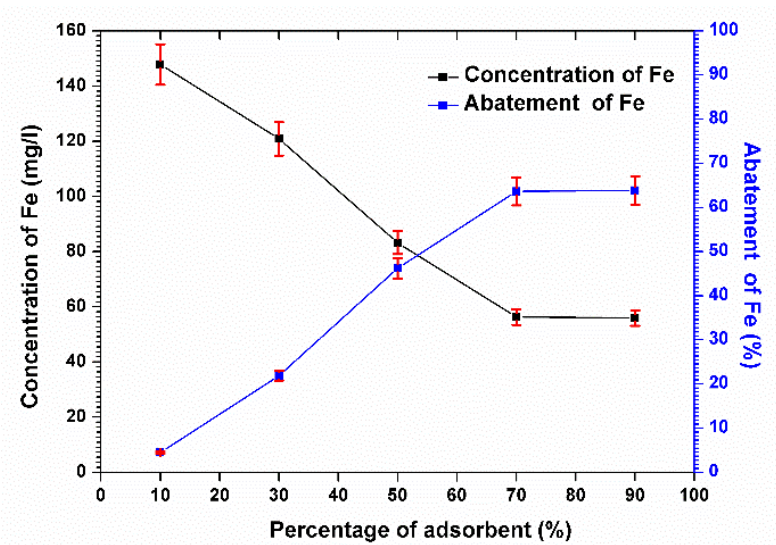

Fig. 14. Concentration and reduction of iron.

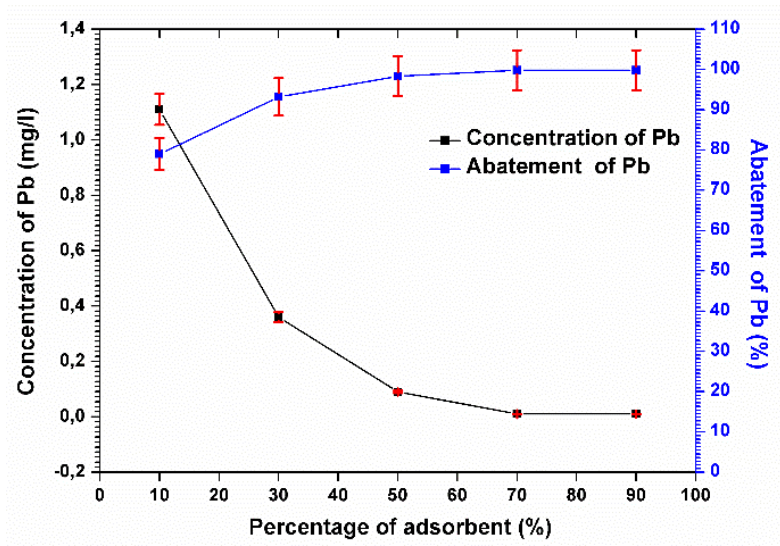

Fig. 15. Concentration and reduction of lead.

\section{Conclusion}

In this study, we studied the effectiveness of the treatment of heavy metals and microelements by bentonite. The results obtained show that the natural clay was a potential and promising adsorbent for the removing heavy metals and microelements by bentonite from an aqueous solution. Yet, natural clay is an inexpensive adsorbent that can remove up to $99.81 \%$ of lead and $63.87 \%$ of iron for bentonite mass loadings of about $80 \%$. This research allows to optimize the adsorption conditions but requires understanding the adsorption kinetics is necessary for the adsorption performance of bentonites.

\section{Nomenclature}

CH : Inorganic clays of high plasticity.

CL : Mineral clays with low to medium plasticity.

COD : Chemical Oxygen Demand.

$\mathrm{Cu}$ : Uniformity coefficient.

LL : Liquidity limit.

ML : Inorganic silts and very fine sands with very low plasticity. 
OH/MH : Organic silts and clays of medium plasticity. OL : Organic silts and silt-clay mixtures of low plasticity. OMW : Olive Mill Wastewater (margin).

PI : Plasticity index.

PL : Plasticity limit.

TKN : Total Nitrogen Kjeldahl

Ws : Shrinkage limit.

\section{Compliance with ethical standards}

\section{Conflicts of Interest}

The authors declares that there are no conflicts of interest regarding the publication of this manuscript.

Acknowledgements We thank the anonymous reviewers for their remarks which have helped improve the manuscript.

\section{REFERENCES}

1. G. Azizi, M. Layachi, M. Akodad, A. I. Martín garcía, and D. R. Yáñez-Ruiz, M. Baghour, H. Ait Hmeid, H. Gueddari, A. Moumen, E3S Web of Conferences, 240, (2021).

2. A. Roig, M. L. Cayuela, M. A. Sánchez-Monedero, Waste. Manag., 26, 9 (2006).

3. P. Vossen, HortScience., 42, 5 (2007).

4. C. Maraveas, Polymers., 12, 5 (2020).

5. D. Bouknana, B. Hammouti, R. Salghi, S. Jodeh, A. Zarrouk, I. Warad, A. Aounitia, M. Sbaa, J. Mater. Environ. Sci., 5, 4 (2014).

6. D. P. Zagklis, C. S. Papageorgiou, C. A. Paraskeva, Sustainability, 13, 4 (2021).

7. J. Duruibe, M. O. Ogwuegbu, C. Ogwuegbu, J. N. Egwurugwu. International Journal of physical sciences, 2, 5 (2007).

8. G. Azizi, M. Layachi, M. Akodad, H. Ngadi, M. Baghour, A. Skalli, M. Ghalit, E. Gharibi, A. Moumen. Assessment of Heavy Metals (Fe, Cu and Ni) Contamination of Seawater and Mussel, Mytilus Galloprovincialis, from Al Hoceima Moroccan Coasts: Heavy Metal Concentrations in Mytilus Galloprovincialis." In Proceedings of the 4th Edition of International Conference on Geo-IT and Water Resources 2020, Geo-IT and Water Resources, March 2020, pp. 1-6 (2020).

9. N. Calace, E. Nardi, B. M. Petronio, M. Pietroletti, Environ. Pollut., 118, 3 (2002).

10. P. B. Tchounwou, C. G. Yedjou, A. K. Patlolla, D. J. Sutton, Mol. Clin. Environ. Toxicol., 101, (2012).

11. J. H. Duffus, Pure and applied chemistry, 74, 5 (2002).

12. G. Azizi, M. Layachi, M. Akodad, M. Baghour, M. Ghalit, E. Gharibi, H. Ngadi, A. Moumen. Ocean Science Journal, 55, 3 (2020).

13. M. Pell, F. Nyberg, American Society of Agronomy, Crop Science Society of America, and Soil Science Society of America, 18, 4 (1989).

14. N. Muhammad, S. Siddiqua, Mater. Today Proc., (2021).

15. H. Ait Hmeid, M. Akodad, M. Baghour, A. Moumen, A. Skalli, G. Azizi, E3S Web of
Conferences, 234, 00092 (2021).

16. H. Ait Hmeid, M. Akodad, M. Aalaoul, M. Baghour, A. Moumen, A. Skalli, A. Anjjar, P. Conti, A. Sfalanga, F.R. Khyabani, S. Minucci, L. Daoudi, Geol. Soc. London, Spec. Publ., 502, 1 (2020).

17. H. Ait Hmeid, M. Akodad, M.Baghour, M. El Gattafi, A. Moumen, A.Aknaf, L. Daoudi, M. Aalaoul, Characterization and Valuation of Clays in the North Eastern Region, in EuroMediterranean Conference for Environmental Integration (Springer, Cham), November 2017, Sousse, Tunisia (2017).

18. H. Ait Hmeid, M. Akodad, M. Aalaoul, M. Baghour, A.Moumen, A.Skalli, L. Daoudi, Mater. Today Proc., 13, (2019).

19. H. Ait Hmeid, M. Akodad, M. Aalaoul, M. Baghour, A. Skalli, L. Daoudi, International Journal of Development Research, 10, (2020).

20. R. Chantrell, J. Popplewell, S. Charles, IEEE. Trans. Magn., 14, 5 (1978).

21. J. Środoń A. D. Victor, K. Douglas, McCarty, CC H. Jean, D. E. Dennis, Clays and Clay Minerals, 49, 6 (2001).

22. F. Ateeq, Chemical Removal of Total Phosphorus from Wastewater to Low Levels and Its Analysis, Theses and Dissertations (Comprehensive), (2016).

23. ASTM D427. Standard Test Method for Shrinkage Factors of Soils by the Mercury Method, ASTM International, United States (1998).

24. J.B. Kouassi, M. Cisse-camara, D.E. Sess, G.G. Tiahou, A.A. Monde, F.Y. Djohan, Bulletin de la Société Royale des Sciences de Liège, 82, (2013).

25. E. Campos, M. Almirall, X. Flotats, Anaerobic digestion of solid fraction of pig slurry, In Proc. of Int. Symposium on Anaerobic Digestion of Solid Waste, (2002).

26. I. Vyrides, D. C. Stuckey, Bioresour. Technol., 100, 2 (2009).

27. A. Najafi and M. Hashemi, Int. J. Environ. Anal. Chem., (2020).

28. P. M. Goupy, P. J. A. Varoquaux, J. J. Nicolas, J. J. Macheix, J. Agric. Food Chem., 38, 12, (1990).

Y. Bachra, A. Grouli, F. Damiri, A. Bennamara, Results in Materials, 8, (2020).

29. A. Kozhakhmetova, Statistical Analysis on particle size distributions and empirically estimated geotechnical design parameters, Thesis (1995).

30. S. H. Yalkowsky, S. Bolton, Pharm. Res., 7, 9 (1990).

31. A. Numata and S. Mori, Limits in the gradation curves of liquefiable soils, in the $13^{\text {th }}$ World Conference on Earthquake Engineering Vancouver, B.C., Canada, 1190 (2004).

32. H. Ouhaddouch, A. Cheikh, M. O. B. Idrissi,1 M. Draoui, M. Bouatia, J. Spectrosc., vol. (2019).

33. J. Madejová, M. Janek, P. Komadel, H.-J. Herbert, H. C. Moog, Appl. Clay Sci., 20, 6 (2002).

34. Y. He, Z. Wu, L. Tu, Y. Han, G. Zhang, C. Li, Appl. Clay Sci., 109, 110 (2015).

35. A. Sarkar, R. B. Dipak, C. D. Samar, B. S.Dwivedi, R. Bhattacharyya, R. Kumar, K. K. Bandyopadhyay M. Saha, G. Chawla, J. Kumar Saha, Ashok Kumar 
Patra, Carbohydrate Polymers, 259 (2021).

36. S. Barakan, V. Aghazadeh, A. S. Beyragh, S. Mohammadi, Environ. Dev. Sustain., 22, 6 (2020).

37. M. Hayati-Ashtiani, Particulate Science and Technology, 30, 6 (2012).

38. D. Dubber, F. N. Gray. Journal of Environmental Science and Health, 45, 12 (2010).

39. M. Achak, W. Boumya, N. Ouazzani, L. Mandi, Ecol. Eng., 136, (2019).

40. J.-M. Tatibouët, E. Guélou, J. Fournier, Top. Catal., 33, 1 (2005).

41. H. Cheng, P. Hong, Contaminants of Emerging Concern in Water and Wastewater, (2020).

42. M. Jannah, S. Mulyati, C. M. Rosnelly, S. Muchtar, The influences of operating conditions on the removal of Fe (II) in water by adsorption using bentonite as a low-cost adsorbent. In Conference Series: Materials Science and Engineering, IOP, February 2021, 1087, 1 (2021). 